\title{
Iniciativas Kaingang de decolonização da cidade ${ }^{1}$ Kaingang initiatives of city decolonization
}

\author{
Ernesto Pereira Bastos Neto ${ }^{2}$ \\ Luís Fernando da Silva Laroque ${ }^{3}$
}

\footnotetext{
${ }^{1} \mathrm{O}$ estudo insere-se no Projeto de Extensão História e Cultura Kaingang e no Projeto de Pesquisa "Identidades étnicas em espaços territoriais da Bacia Hidrográfica Taquari-Antas/RS" da Universidade do Vale do Taquari - Univates e contam com auxílio financeiro desta Universidade e da Fundação de Amparo à Pesquisa do Rio Grande do Sul (FAPERGS).

2 Graduando em História/Licenciatura e bolsista de extensão no Projeto História e Cultura Kaingang, da Universidade do Vale do Taquari - Univates. E-mail: ernesto.bastos@univates.br

${ }^{3}$ Doutorado em História. Professor do Curso de História e do Programa de Pós-Graduação em Ambiente e Desenvolvimento (PPGAD) da Universidade do Vale do Taquari. E-mail: lflaroque@univates.br
} 


\section{Resumo:}

$\mathrm{O}$ presente estudo analisa $\mathrm{o}$ potencial decolonial de uma festa realizada pela comunidade Kaingang Foxá, no município de Lajeado/RS, para a qual a comunidade não indígena foi convidada a conhecer a cultura Kaingang. Ainda que marcada pela sobreposição territorial e a multiplicidade étnica, a região do Vale do Taquari/RS costuma ser identificada como berço de imigrantes, alemães e italianos principalmente. Neste contexto, as reocupações territoriais dos Kaingang, desde o final do século $X X$, intensificam o estranhamento e preconceito por parte da população local. Neste sentido, o presente texto além de evidências históricas da presença indígena nestes espaços, apresenta uma experiência de mediação da participação de estudantes da educação básica na realização de um ritual tradicional Kaingang, com vistas a promover princípios fundamentais da Lei $11.645 / 08$, como o ensino sob o ponto de vista do protagonismo indígena.

Palavras-chave: Extensão Universitária, Educação Decolonial, Kaingang, História Indígena.

\section{Abstract:}

This study analyzes the decolonial potential of a party held by the Kaingang Foxá community, in the municipality of Lajeado / RS, to which the non-indigenous community was invited to know the Kaingang culture.. Although marked by territorial overlap and ethnic multiplicity, the region of Vale do Taquari / RS is usually identified as the cradle of immigrants, mainly Germans and Italians. In this context, the Kaingang territorial reoccupations since the late twentieth century have intensified the strangeness and prejudice of the local population. In this sense, the present text, besides historical evidences of indigenous presence in these spaces, presents an experience of mediating the participation of students of basic education in the performance of a traditional Kaingang ritual, with a view to promoting fundamental principles of Law 11,645 / 08, such as teaching from the point of view of indigenous protagonism.

Key-Words: University Extension; Decolonial Education; Kaingang; Indigenous History.

Localizada do município de Lajeado, a Terra Indígena Foxá é uma retomada de parte do território expropriado aos Kaingang em meados do século XIX. A identidade territorial da cidade e região, por outro lado, enfatiza 
o caráter eurocêntrico, dando ênfase aos processos de ocupação por imigrantes alemães e italianos de regiões consideradas "vazias" ou desocupadas.

Há mais ou menos um ano, uma colega historiadora, professora nas redes pública e privada de educação básica, relatou um episódio que merece ser retratado, pois ilustra precisamente aquilo que se pretende demonstrar no presente trabalho. Contou ela que certo dia, não faz muito, um professor indígena foi até uma escola da rede privada em que ela leciona, no município de Lajeado/RS, interessado em divulgar as atividades de seu pretenso projeto, cujo objetivo consistia em apresentar a cultura indígena nas escolas da região.

A profissional que o recebeu, sabendo da afinidade da referida professora com a temática indígena, direcionou-o a ela. Qual não foi sua surpresa quando verificou que o título do projeto apresentado era: "História e Cultura Kaingang em Territórios da Bacia Hidrográfica Taquari-Antas", idêntico ao título de então do projeto de extensão ao qual ela própria era voluntária, conforme retomaremos na sequência deste estudo.

Em nosso ponto de vista, esta breve história ilustra algo que Marshall Sahlins alertava mais de vinte antes atrás: “[...] o imperialismo não está lidando com amadores nesse negócio de construção de alteridades ou de produção de identidades" (SAHLINS, 1997a, p. 133).

Conforme exposto, História e Cultura Kaingang em Territórios da Bacia Hidrográfica Taquari-Antas é o título anterior do atual Projeto de Extensão História e Cultura Kaingang, desenvolvido pela Universidade do Vale do Taquari - Univates. O Projeto, cujo objetivo é atuar junto das comunidades Kaingang da região, existe desde o ano de 2009.

Atualmente este Projeto está vinculado ao Curso de Graduação em História do Centro de Ciências Humanas e Sociais junto ao Programa de Extensão Direitos Humanos, Inclusão e Acessibilidade da Universidade do Vale 
do Taquari - Univates, e também se insere ao Programa de Pós-Graduação em Ambiente e Desenvolvimento da mesma instituição.

O objetivo do presente trabalho é apresentar e analisar o potencial educativo-decolonial de um evento/ritual realizado na Terra Indígena Foxá, que teve atividades voltadas ao público não indígena. Para tanto, faz-se necessária breve contextualização a respeito das ocupações humanas em territórios da Bacia Hidrográfica do Rio Taquari-Antas, bem como a identificação de disputas envolvendo memórias (POLLAK, 1992) e identidades territoriais no Vale do Taquari (NICOLINI, 2013).

\title{
(DES) CONSTRUÇÃO DE UMA REGIÃO SOB A ÉGIDE DO PROGRESSO
}

Região, espaço, lugar, território, fronteiras, são categorias que ajudam a pensar sobre a ocupação do ambiente pelos seres vivos, em que pese a carga, muitas vezes ideológica, que subjaz à construção de cada uma destas definições. Helen Osório (1990) reflete a respeito da construção do espaço platino, sob a perspectiva do materialismo histórico. Embora algumas observações devam ser feitas, sobretudo no que concerne ao destino das populações indígenas, a análise da autora é elucidativa:

\begin{abstract}
A eliminação do conteúdo histórico do espaço se opera quando sua configuração é dada a partir de um determinado momento, fixo, sem considerar seu movimento, seu processo constitutivo-constituinte, ocultando-se a ideia de transformação, ou seja, quando abstrai-se de sua configuração a ação humana no tempo, temos um espaço unidimensional. O espaço, no entanto, não é estático, ele é construído, é um dos produtos da relação que o homem, na produção e reprodução de sua existência, estabelece com a Natureza, que por sua vez é por ele transformada (OSÓRIO, 1990, p. 24).
\end{abstract}

A produção de narrativas laudatórias da trajetória dos grupos hegemônicos constitui-se um dos mecanismos de naturalização de processos 
que são históricos e que engendram violência, opressão, resistência, assim como costumam preservar "memórias subterrâneas" (POLLAK, 1992). Neste sentido, a porção territorial, por exemplo, que atualmente é designada como Vale do Taquari, pode ser identificada enquanto parte dos territórios de diferentes populações, cuja territorialidade não corresponde aos limites da geopolítica oficial.

Observa-se, no entanto, que os historiadores e memorialistas por muito tempo deram ênfase em seus textos aos aspectos da história que se alinham aos projetos políticos do Estado brasileiro (NICOLINI, 2013). Deste modo, os atores mais lembrados são os imigrantes europeus (sobretudo os de origem germânica e italiana) que passaram a colonizar a região em questão a partir da segunda metade do século XIX.

Entende-se, atualmente, que apropriação do espaço platino pela Coroa Portuguesa ocorreu no contexto da disputa com a Monarquia Espanhola, remontando à fundação da vila militar de Rio Pardo, em meados do século XVIII. Em função da instabilidade das fronteiras, as terras e florestas entre os campos de Viamão e Rio Pardo foram distribuídas como sesmarias para lusobrasileiros envolvidos militarmente na defesa dos interesses portugueses. Também foram concedidas datas de terra, isto é, propriedades menores, sobretudo para imigrantes açorianos. Osório (1990) também indica que neste período já havia compra e venda de terras neste espaço. Evidencia-se, portanto, alguma heterogeneidade na conformação do território que posteriormente será denominado como Vale do Taquari.

A partir da segunda metade do XIX, as grandes fazendas foram sendo loteadas e vendidas para imigrantes alemães e também descendentes destes, provenientes de colônias mais antigas, principalmente São Leopoldo. O movimento imigratório implicou diretamente no cotidiano Kaingang. 
Considerando que o presente trabalho versa a respeito de atividades desenvolvidas pelo Projeto de Extensão com este povo indígena em específico, é pertinente apresentar aspectos da trajetória desta população e da relação que mantém com os territórios do Vale do Taquari, mais precisamente, da Bacia Hidrográfica do Rio Taquari-Antas.

\section{PANORAMA GERAL DA HISTÓRIA KAINGANG}

Kaingang é o etinônimo de autodesignação de um povo indígena, falante de língua Macro-Jê, que atualmente reside em aldeias demarcadas ou autodemarcadas, distribuídas entre os atuais estados de São Paulo, Paraná, Santa Catarina e Rio Grande do Sul. Kaingang significa gente do mato ou gente que come pinhão. Como sabemos, os etnônimos têm mais sentido externa do que internamente ao grupo. Internamente este povo se organiza a partir de uma estrutura dualista, que confere a cada membro do grupo uma marca de descendência clânica, por herança patrilinear, quais sejam: rá téj (marca comprida/Kamé) rá ror (marca redonda/Kanhru) (VEIGA, 1994).

A ocupação pelos ancestrais dos atuais Kaingang e Xokleng/Laklãnõ (povos Jê do Sul), de territórios que passaram a ser chamados brasileiros, é amplamente comprovada por pesquisas arqueológicas, que evidenciam mais de dois mil anos de sua presença sistemática no Planalto Meridional. Por volta de três mil anos atrás, um aumento populacional onde atualmente se localiza a região amazônica, teria estimulado a migração de grupos falantes de língua Jê e Tupi-Guarani, que colonizaram as porções setentrional e meridional do atual território brasileiro (NOELLI; SOUZA, 2017). Alguns séculos mais tarde os Jê subdividiram-se, dando origem aos atuais Kaingang e Xokleng/Laklãnõ, povos 
que embora falem línguas de um mesmo tronco (Macro-Jê), são culturalmente diferentes.

Com relação à invasão luso-brasileira dos territórios Kaingang, este processo se deu de forma sistemática a partir do século XVIII, iniciando pelas expedições paulistas aos campos de Guarapuava e Palmas, onde mais tarde foram estabelecidos os primeiros acordos entre representantes da Coroa Portuguesa e caciques principais ( $P a^{\prime} i ́$ mág) Kaingang - que na época eram chamados pelos luso-brasileiros de coroados (LAROQUE, 2000).

Entre os anos de 1835-1845 nos territórios da Província de São Pedro, teve lugar a mais longa guerra civil da história do Estado brasileiro. Imediatamente depois da pacificação, foi intensificada a vinda de imigrantes de origem germânica para o extremo sul do Império. Neste contexto, uma série de legislações, como o Regulamento de Missões (1845) e a Lei de Terras (1850), regulada por decreto em 1854, passam a implicar diretamente na expansão de colônias agrícolas sobre os territórios Kaingang.

A região da Bacia Hidrográfica do Rio Taquari-Antas recebeu significativas levas de imigrantes, o que acarretou reações das parcialidades Kaingang que ocupavam aquele espaço. Segundo Laroque (2000), pelo final da década de 1830 este território correspondia especificamente aos domínios do cacique Doble, subordinado ao cacique principal Braga.

Os episódios que a historiografia recente pôde interpretar a respeito das lideranças Kaingang contrariam uma visão mônada do ser indígena, tanto aquela do bom selvagem da literatura romântica, quanto a do índio incapaz, apregoada pelos adeptos do positivismo (LAROQUE, 2000; FRANCISCO, 2013). A trajetória de Doble durante o século XIX, por exemplo, inclui sublevação contra seu Principal, aliança com fazendeiros locais, negociação com presidentes de província, conquista de privilégios para si e o seu grupo, ou seja, 
uma série de estratégias acionadas por ele, para auferir objetivos que a conjuntura lhe fazia vislumbrar.

Entre as últimas décadas do século $\mathrm{XIX}$ e as primeiras do $\mathrm{XX}$, os territórios Kaingang foram envoltos por processos de avanço de frentes pioneiras do capitalismo nascente. Com o advento da República e o empoderamento de uma facção política ideologicamente alinhada ao Positivismo também em nível estadual, a questão indígena no Rio Grande do Sul auferiu um caráter peculiar. Sob o governo do Partido Republicano Riograndense (PRR) a "pasta indígena" foi entregue à Diretoria de Terras e Colonização, que: [...] Objetivava exercer a "Proteção Fraternal" aos nativos do Rio Grande do Sul (RODRIGUES, 2007, p. 23).

$\mathrm{Na}$ esteira dos projetos de desenvolvimento econômico, a segunda metade do século $X X$ foi especialmente violenta para os povos indígenas no Brasil, e com os Kaingang não foi diferente. Neste período, as Terras Indígenas estavam sob a tutela do órgão indigenista brasileiro, o Serviço de Proteção aos Índios (SPI). Proteção é uma expressão bastante ambígua neste caso, de modo que o órgão tinha como padrão de atuação a proteção dos interesses da sociedade nacional e não dos indígenas (NÖTZOLD; BRINGMANN, 2013).

Após o golpe de 1964, bem como durante a ditadura civil-militar brasileira, a violação dos direitos humanos - práxis do regime - atingiu também as Terras Indígenas Kaingang, violações que, diga-se de passagem, ocorreram em larga medida durante os tempos do SPI. Em função da extinção do órgão em 1967, o Regime Militar criou a Fundação Nacional do Índio (FUNAI).

A Funai se constituiu como o órgão capaz de desenvolver nas comunidades indígenas a política imposta pelos militares, que implicava na repressão e no controle, associados ao desenvolvimento econômico através da exploração dos recursos naturais das próprias Terras Indígenas. Na lógica militar, nada mais apropriado que a tutela para manter o controle sobre os indígenas (BRINGHENTI, 2015, p. 155). 
No ano de 1978, já no contexto de ampla articulação do movimento indígena brasileiro, se inicia uma reação Kaingang às expropriações, desencadeada em muitas terras indígenas no sul do Brasil que se encontravam ocupadas por posseiros, isto é, agricultores nacionais. Estes episódios na história recente deste povo ficaram conhecidos como expulsão dos posseiros, marcando uma retomada definitiva da autonomia do povo Kaingang sobre parte dos seus territórios (BRINGHENTI, 2015).

Com a Constituição Federal de 1988 a tutela foi extinta e os povos indígenas do Brasil conquistaram o direito de ser reconhecidos e respeitados em suas especificidades culturais. Além da liberdade de ir e vir e de se representarem judicialmente, na condição de cidadãos brasileiros, reconhecida aos nativos pela primeira vez desde que a invasão europeia se iniciou, os indígenas conquistaram o direito de autoidentificarem seus territórios ancestrais que foram expropriados, e é neste contexto que aldeias Kaingang são refundadas no Vale do Taquari, assim como em outras regiões e cidades pelo sul do Brasil.

RETOMADAS TERRITORIAIS NA BACIA HIDROGRÁFICA DO RIO TAQUARI-ANTAS E A ATUAÇÃO DO PROJETO DE EXTENSÃO HISTÓRIA E CULTURA KAINGANG

Como foi dito, a partir da última década do século XX tornou-se constante a retomada por parte dos Kaingang de porções do seu tradicional território, que haviam sido expropriadas pela expansão do Estado brasileiro. Estas retomadas são articuladas a partir de uma forma de atuação que pode ser chamada de cosmopolítica. Ou seja, são movimentos políticos orquestrados pela ontologia Kaingang, envolvendo, portanto, termos e atores não humanos e extra-humanos ou mesmo outras formas de humanidade (FREITAS, 2005). 
$\mathrm{Na}$ região hidrográfica do Lago Guaíba existem atualmente onze retomadas, que são consideradas pelos Kaingang ëmãa, ou seja, aldeias fixas. As famílias residentes nestas ëmã procuram idealmente prover sustento exclusivamente da venda de artesanato, empregando-se em outras atividades quando é necessário. $\mathrm{O}$ artesanato permite aos Kaingang reproduzir um ciclo econômico consoante ao ethos caçador-coletor do povo. Esta reprodução passa pelo estabelecimento de acampamentos provisórios (wãrë) para coleta de material e venda das obras de arte que confeccionam. Deste modo, os Kaingang realizam um processo de (re) territorialização, ou seja, ressignificam espaços como a cidade, por exemplo, a partir de seus próprios códigos socioculturais (TOMMASINO, 1995).

Aquino (2008) observa inclusive a (re)produção nos territórios em contexto urbano, da organização política interaldeã vivenciada nas aldeias grandes, isto é, reservas e Terras Indígenas Kaingang demarcadas, de onde são oriundos a maioria destes sujeitos. Um elemento central da referida organização é a realização de festividades como casamentos, Semana dos Povos Indígenas, Encontro dos Kujà, Kiki koi, entre outras. As festas sempre ocuparam papel de destaque na cultura Kaingang, sendo o momento de estabelecer ou reforçar alianças políticas por meio da comensalidade, e também de promover os casamentos, elemento fundamental para a estabilidade política entre aldeias vizinhas (TOMMASINO, 1995).

A Emã Foxá, localizada no atual município de Lajeado/RS, Bacia Hidrográfica do Rio Taquari-Antas, é uma das aldeias integrantes deste “aglomerado político-cerimonial” da região do Lago Guaíba ou do litoral, como prefere Aquino (2008). Fundada no início do ano 2000, apresenta um histórico de reivindicações e conquistas muito ilustrativo dos processos de retomada territorial descritos acima em linhas gerais (LAPPE, 2015; LAPPE; LAROQUE, 2018). 
Mais especificamente situada na RS-129, próxima ao limite com o município de Cruzeiro do Sul/RS, esta aldeia é formada por aproximadamente cento e cinquenta pessoas. A atuação do grupo de pesquisa ao qual o Projeto de Extensão faz parte, junto desta comunidade, é anterior à própria existência do Projeto e pode ser mais bem compreendida a partir da leitura de Oliveira (2010), Gonçalves (2011), Lappe (2012; 2015) e Prestes (2018).

Estas pesquisas mencionadas chamam atenção, entre outras coisas, para o preconceito da sociedade local com as comunidades indígenas que voltaram a estes espaços (LAPPE, 2015). Uma das questões que mais vezes causou embaraço e constrangimento para a comunidade está diretamente associada ao desconhecimento da população, inclusive dos órgãos públicos, sobre o modo de ser deste povo:

\footnotetext{
Os Kaingang, na cidade de Lajeado, enfrentam um (pre)conceito em relação à venda do artesanato por crianças. Mas, como enfatizado pela liderança, a criança vender o artesanato na cidade é próprio da cultura Kaingang, pois é uma forma de educar as crianças, educar para que, no futuro, se não tiverem emprego, possam fazer o artesanato e comercializar para poderem sustentar sua família (LAPPE, 2015, p. 169).
}

Neste sentido, o Projeto de Extensão atua realizando a investigação das necessidades destas comunidades, que muitas vezes iniciam seus processos de retomada em situações bastante precárias de acesso aos direitos fundamentais, como saneamento básico, escolarização e atendimento de saúde (observando-se também as especificidades constitucionalmente garantidas aos povos indígenas).

Ao invés de realizar um apanhado cronológico da atuação do Projeto, optou-se por apresentar uma atividade específica, com vistas a ilustrar o protagonismo assumido pelas comunidades para identificar e superar suas próprias dificuldades, de forma absolutamente afastada das noções de 
isolamento, refração e beligerância constante, que costumam aparecer nas representações sobre os povos indígenas.

Quando da criação do Projeto, no ano 2009, o objetivo era conhecer a história e as demandas de duas comunidades Kaingang existentes nas proximidades do então Centro Universitários Univates, uma delas situada no município de Lajeado/RS e outra no de Estrela/RS. Dentre os aspectos mais apontados pelos indígenas está o preconceito da população regional, marcado pelo total desconhecimento a respeito da realidade dos povos indígenas (SILVA, 2011; LAPPE, 2012).

Deste modo, um dos eixos de ação do Projeto de Extensão tem sido a promoção de atividades voltadas à redução desse preconceito. Inicialmente, atuava-se, sobretudo, por meio da realização de palestras nas escolas da rede básica de educação. Entre os anos de 2009 e 2016, praticamente todas as escolas dos trinta e seis municípios compreendidos no Vale do Taquari receberam ao menos uma palestra. Muitas escolas, no entanto, foram parceiras para a realização de atividades sistemáticas.

Não obstante, a instituição mantenedora incluiu as atividades do Projeto de Extensão enquanto mecanismo para o cumprimento das exigências da Lei 11.645/08, solicitando também que sejam realizadas palestras com graduandos (as) da instituição, atividade que ocorre na disciplina de Temas Contemporâneos, que está na matriz curricular de todos os cursos de graduação da Univates.

Atualmente a abrangência do Projeto ampliou-se, contemplando a Bacia Hidrográfica do Rio Taquari-Antas e adjacências, de modo que o objetivo da edição 2016-2019 é:

Atuar com as comunidades indígenas Kaingang, que se encontram em territórios localizados principalmente nos municípios de Lajeado, Estrela, Tabaí e Farroupilha, visando a conhecer a história, os traços culturais e as condições atuais de sustentabilidade, meio ambiente, 
educação e saúde indígena (PROJETO DE EXTENSÃO, 2016, p. 5).

A relação construída entre o Projeto de Extensão e a comunidade, no decorrer destes mais de 10 anos parece ter sido elemento fundamental para que no ano de 2018 tenha sido possível a participação ativa do grupo em um evento de grande dimensão realizado pela comunidade. Em meados de 2017, Kassiane Schwingel, vinculada ao Conselho de Missões entre Índios (COMIN) e voluntária do Projeto de Extensão, procurou a coordenação do projeto para comunicar que os Kaingang da Foxá planejavam realizar um Kiki koi e gostariam de contar com o auxílio do Projeto.

\section{O KIKIKOI NA TERRA INDÍGENA FOXÁ, EDIÇÃO $2018^{4}$}

A etnologia Kaingang associada aos estudos de Curt Nimundajú desenvolveu um modelo interpretativo das instituições Kaingang, que coloca o veingreinyã, ou Kiki koi (festa de comer Kiki), no centro da vida cerimonial deste povo (VEIGA, 1994, TOMMASINO, 1995; CRÉPEAU, 2006; CRÉPEAU; ROSA, 2018; AQUINO, 2018).

"O Kiki koi é uma festa ao mesmo tempo sagrada e profana" (VEIGA, 1994, p. 165), a festa é realizada por solicitação de alguém cujo um parente faleceu e esta pessoa se preocupa com o bom destino de sua alma. Para a festividade são convidadas aldeias do círculo de reciprocidade da comunidade que sediará o evento. $\mathrm{O}$ "Kiki parece ser uma oportunidade dos espíritos dos

\footnotetext{
${ }^{4}$ No ano de 2013, as lideranças da Terra Indígena Foxá, sobretudo o então cacique Francisco Rokag dos Santos, realizaram esta cerimônia pela primeira vez nesta aldeia. Naquela oportunidade, o coordenador e integrantes do Projeto de Extensão História e Cultura Kaingang foram convidados para participar (BUSOLLI, 2015)
} 
mortos poderem voltar à aldeia dos vivos. Seria um momento onde os vivos e os mortos estão festejando no mesmo espaço" (VEIGA, 1994, p. 162).

Na década de 1990, segundo Veiga (1994), apenas a comunidade de Xapecó realizava o Kiki koi, a maioria das demais comunidades havia deixado de declarar a realização do ritual, sobretudo em função da pressão feita por organizações confessionais, católicas e pentecostais.

Não obstante a complexidade ritual, no presente trabalho pretende-se dar ênfase ao potencial educativo-descolonial das atividades realizadas, sem ignorar as camadas mais visíveis do fenômeno. Sem, no entanto, a pretensão de analisar o evento em sua dimensão ritual e do xamanismo Kaingang. Neste sentido, apresentam-se a partir daqui algumas informações sobre o processo que antecedeu a realização do ritual, de acordo com os registros realizados em diários de campo e fotografias, que fazem parte do acervo do Projeto de Extensão, com exceção do último dia do evento, que não foi aberto à comunidade externa e, portanto, entende-se que merece abordagem específica em outro texto. Aquino (2018) realizou abordagem etnográfica de parte deste ritual.

No dia dezesseis de agosto de 2017, ocorreu então a primeira reunião na comunidade para conversar sobre o evento. Os indígenas redigiram uma ata desta reunião e de todas as demais subsequentes. Desde este momento os indígenas manifestaram o interesse em realizar uma semana cultural e solicitaram auxílio, sobretudo, para elaborar o projeto escrito e divulgar amplamente o evento para a comunidade não indígena, com vistas a convidar escolas, imprensa, órgãos públicos e autoridades da região para prestigiar. Ficou definido que o evento seria realizado na primeira semana de abril do ano de 2018.

A elaboração do evento envolvia a preocupação de que nada desse errado, pois isso poderia trazer problemas de ordem cosmológica à 
comunidade. Para tanto, observou-se que as demandas prioritárias eram a presença dos Kujà , para fazer o ritual, assim como eram imprescindíveis o mel, as plantas usadas na bebida e o tronco de uma árvore específica para fazer o cocho/konkéi, preferencialmente o pinheiro - fág (araucária angustifólia). Todavia, a espécie utilizada acabou sendo o açoita-cavalo (Luehea Divaricata).

Além disso, muitas outras questões fizeram parte do horizonte de preocupações do grupo. Viabilizar o transporte dos Kujà, residentes em Nonoai, angariar a quantidade e variedades suficientes de mel para a bebida, os alimentos necessários para oferecer o almoço aos visitantes, entre outras. Tudo isso foi arrolado em uma lista de necessidades, encaminhada aos órgãos que poderiam ser parceiros: FUNAI, SESAI, COMIN, CIMI (Conselho Indigenista Missionário), EMATER, Pastoral da Terra, Secretaria de Cultura do Município de Lajeado, e outras organizações.

Os encontros na Terra Indígena para tratar do projeto passaram a ter periodicidade praticamente semanal. Todavia, o processo foi conduzido sempre pelos indígenas, mais especificamente pela liderança da comunidade. Os contatos com a Univates se deram sempre por intermédio do cacique, sendo que a intensificação da presença de integrantes do Projeto de Extensão na comunidade foi acompanhada muito de perto por esta liderança, que fazia questão de salientar a importância de que qualquer combinado fosse feito sempre com o cacique, a fim de evitar mal-entendidos.

Entre os meses de outubro e novembro de 2017, os Kaingang da Foxá encaminharam os projetos às entidades parceiras e também os convites do evento às aldeias da região. Deixaram sob nossa responsabilidade encaminhar convites às escolas. Sabendo da necessidade de arrecadação de alimentos, foi

\footnotetext{
${ }^{5}$ A literatura etnológica Kaingang parece concordar que o Kujà ou Kujã é um xamã da tradição Kaingang, e um sujeito capaz de mediar a relação entre os mundos dos vivos e dos mortos, atua guiado por um animal-auxiliar que lhe mostra elementos da floresta, conhecedor da medicina do corpo e do espírito.
} 
combinado solicitar às escolas interessadas em participar do evento, que cada aluno traria um quilo de alimento não perecível. Encaminharam-se convites por e-mail às secretarias de educação e a muitas escolas da região, bem como à $3^{\text {á }}$ Coordenadoria Regional de Educação.

No dia onze de dezembro do mesmo ano, ocorreu uma reunião na Foxá envolvendo funcionários da FUNAI, da SESAI, do COMIN, da Pastoral da Terra além de bolsistas do Projeto de Extensão. Esta reunião foi iniciada por uma apresentação do grupo de dança da comunidade. Logo após, o então cacique Vicente Nurvãnh Garcia e o coordenador do Kiki Vergelino Karen Né Nascimento falaram aos presentes sobre a importância da realização do Kiki:

[...] O cacique explicou cada uma das danças e cantos, enfatizando que representam um resgate cultural e que são um grito de guerra da juventude indígena, pedindo para que a natureza seja respeitada e que sejam valorizados os conhecimentos Kujã. [...]Convocando os ali presentes para que o auxiliem na realização da festividade, pois esta tem um valor simbólico muito importante para a comunidade. $\mathrm{O}$ cacique reitera que a dança traduz a necessidade que os jovens têm de conhecer de perto e aprender com os velhos Kujãs, ressaltando que estes estão envelhecendo, e que com a perda deles, se perde junto, um valor inestimável de aprendizado. [...] Vergelino, inicia sua fala, explicando que a festividade é estritamente cultural, que não é apenas uma festa para comer e "arrastar o pé", já que o grande objetivo é a realização do Kiki. Na sequência, apresentou o projeto, escrito em parceria com os integrantes do Projeto de Extensão História e Cultura Kaingang, ressaltando a importância do apoio que o projeto lhes dá. [...] Ao realizar a leitura do projeto (escrito por nós não-indígena), conseguiu se apropriar do conhecimento ali escrito e após cada trecho, parava para explicar com suas palavras, de forma simples e acessível a todos (DIÁRIO DE CAMPO 11/12/2017, p. 2).

Evidenciou-se que o fato de a SESAI contar com funcionários indígenas é fundamental, pois estes reiteraram a relevância do conhecimento tradicional transmitido pelos Kujà, como instrumento de garantia do direito à atenção diferenciada. Vergelino, em narrativa carregada de emoção, destacou que a festividade estaria sendo realizada em homenagem aos caciques e kujà que haviam morrido recentemente, dando ênfase à perda de Francisco Rokag, homenageado oficial da festividade. 
Como previsto, o evento ocorreu entre os dias cinco e sete do mês de abril de 2018, sendo os dois primeiros dias abertos às visitas e o último dia reservado para os indígenas e pesquisadores convidados. O início do ritual, no entanto, parece ter ocorrido na terça-feira, quando um açoita-cavalo foi "morto" e transformado em konkei. A realização do processo estava absolutamente tomada por simbolismos. Desde a entrada no mato, conduzida pelo cacique, que chacoalhava seu chocalho (zygzyg) na mão direita, enquanto carregava um arco e algumas flechas na esquerda. Atrás do cacique vinha seu pai, o kujà Jorge Garcia, que carregava um ramo de diversas plantas, balançando-o num movimento pendular como se estivesse limpando o caminho, ao mesmo tempo em que entoava cantos em sua língua. Jorge entrou na mata, seguido por sua esposa Maria Constate, seus filhos Pedro que tocava uma flauta de taquara e Lúcia, que também trazia um ramalhete na mão e os demais Kaingang que participaram da atividade.

Assim que a árvore foi escolhida, um imponente exemplar de aproximadamente quinze metros de altura cuja espessura do tronco superava um metro de circunferência, os indígenas cercaram-na e os kujà iniciaram rezas em sua língua, enquanto balançavam em frente à árvore os ramalhetes que empunhavam. Alguns minutos depois, um Kaingang começou a golpear o tronco com um machado. Muitos indígenas se revezaram na tarefa e quando a árvore estava praticamente cortada, mas ainda de pé, o cacique empunhou seu arco e lançou uma flecha, acertando o tronco enquanto este se projetava ao solo. Seguiu-se a esse ato uma série de outros que precederam e se seguiram ao processo de transformar o tronco em um cocho para depositar a bebida ritual (AQUINO, 2018).

No que diz respeito à organização das atividades envolvendo as escolas, o Projeto de Extensão encarregou-se de identificar previamente o número de adesões, enviar listas com os gêneros alimentícios solicitados pela comunidade 
e definir com estas escolas o dia e turno ideal para agendar a visitação. Ao todo, participaram aproximadamente 400 estudantes de 7 escolas da região, conforme registro fotográfico (Figura 1). Além destes, estiveram presentes estudantes de graduação voluntários do Projeto de Extensão, funcionários do posto de saúde do bairro, entre muitas outras pessoas que não foi possível identificar.

Figura 1: Estudantes da educação básica no Cerimonial do Kikikoi na Comunidade Indígena Foxá/Lajeado, em 2018 (Fonte: ACERVO do Projeto Kaingang, 2018).

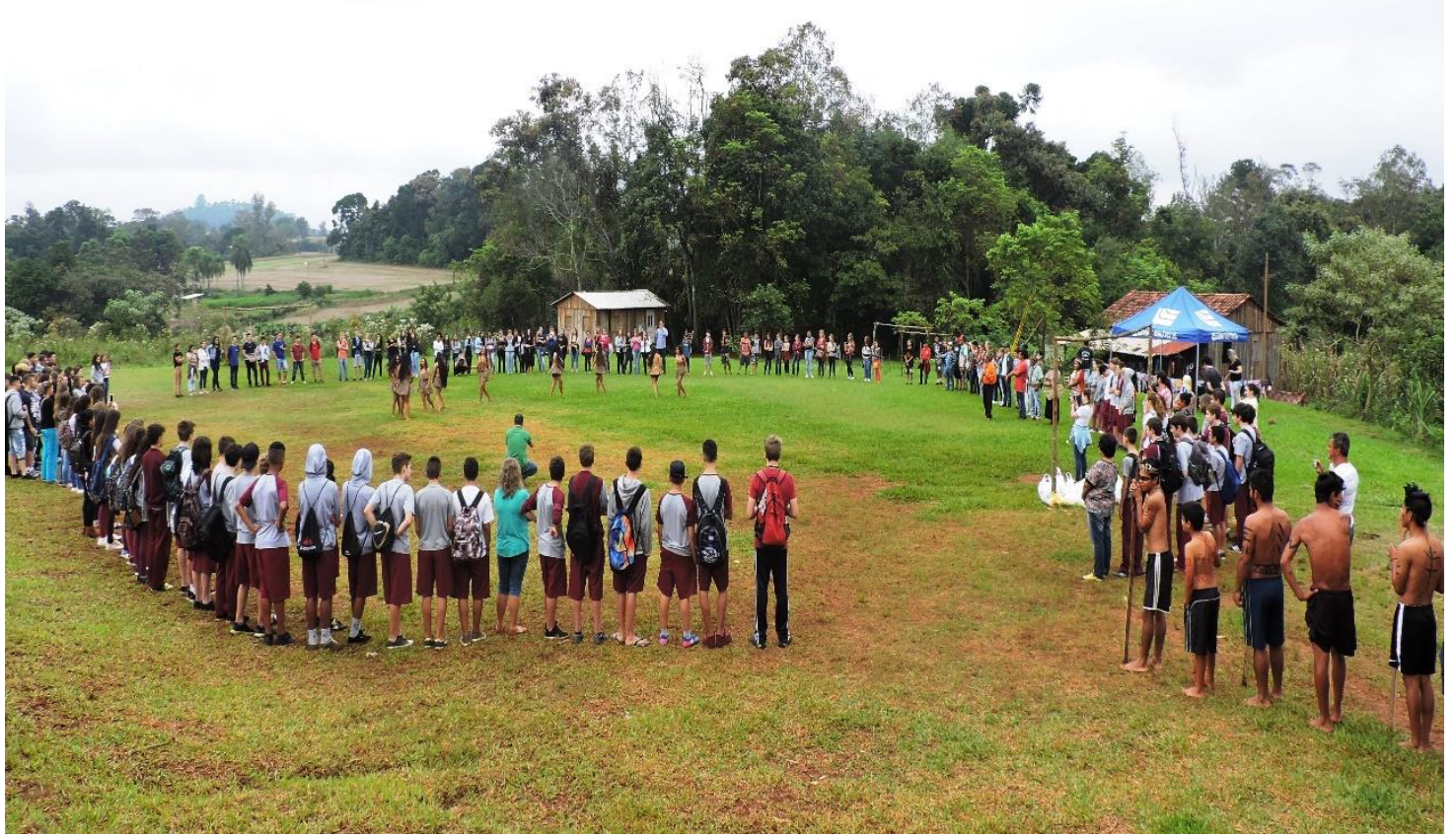

As atividades direcionadas especificamente para os visitantes ocorreram em quatro turnos, entre os dias 5 e 6, manhã e tarde. Foram ministradas pelo cacique e vice, kujà, professores bilíngues da comunidade, entre outras pessoas, sendo possível identificar nos conteúdos temas como história e direitos indígenas, histórico e perspectivas de futuro das relações étnico-raciais abrangendo dimensões continentais e locais, bem como aspectos específicos do povo Kaingang, envolvendo organização social, religiosidade e espiritualidade, 
relações com o meio ambiente, medicina e alimentação tradicional, modo de vida ancestral e importância do artesanato para a reprodução da cultura em contexto urbano.

Além de atividades no estilo palestra, houve apresentações do grupo de danças da comunidade, visita guiada por diversos espaços, além de rodas de conversa promovidas a respeito de educação indígena, educação escolar indígena e cultura Kaingang, realizadas pelo professor bilíngue e os kujà. Outro importante local de trocas e conversas entre anfitriões e visitantes foram os estandes de venda de artesanato, espalhados pelos caminhos da aldeia. Durante a atividade as lideranças chamaram para fazer uso da palavra autoridades e parceiros presentes, dentre os quais um representante do Ministério Público e o coordenador do Projeto de Extensão.

A realização deste evento (não obstante a dimensão etnológica) também pode ser entendida como uma prática educacional decolonial, permitindo a todos os partícipes não apenas a oportunidade de vivenciar as relações étnicoraciais de forma plena e positiva, mas de vislumbrar outro universo possível de ancoragem para o pensamento, uma “opção”, como diria Mignolo (2017).

O pensamento decolonial, argumenta Mignolo (2017), é também uma opção política, que vem sendo marcada por populações subalternas ao redor do mundo e que pode ser ilustrada pelo posicionamento da Conferência de Bandung: “[...] na qual se reuniram 29 países da Ásia e da África. O principal objetivo da conferência era encontrar as bases e a visão comum de um futuro que não fosse nem capitalista nem comunista" (MINGOLO, 2017, p. 14). Isto é, não apenas na dimensão mais geral, dos sistemas de governo, “[...] o pensamento descolonial está hoje comprometido com a igualdade global e a justiça econômica" (MINGNOLO, 2017, p. 15).

A análise da legislação brasileira sobre educação para as relações étnicoraciais, realizada por Oliveira e Candau (2010), demonstra que os dispositivos 
legais preconizam a necessidade de se criar mecanismos de ressignificação das relações entre brancos, negros e indígenas. Acredita-se, portanto, que a experiência proporcionada aos estudantes e professores tem potencial tanto de conferir sentido às atividades que forem propostas em sala de aula sobre história, cultura e atualidade indígena, quanto de fomentar entre professores novas ideias e compreensões sobre o ser e fazer docente, no que diz respeito à questão indígena.

Alguns meses depois da realização do evento, a liderança da comunidade nos convidou para auxiliar na realização de uma nova edição. A razão, segundo afirmam, é que a partir daquela atividade o reconhecimento pelos regionais e até mesmo por órgãos públicos, sobre a autenticidade de sua cultura, passou a refletir positivamente. Vergilino afirma já não suportar ouvir que em "Lajeado nunca teve índio" e que estes eventos promovem a propagação de representações positivas a respeito dos índios (DIÁRIO DE CAMPO, 05/04/2019, p. 5).

Por outro lado, retomando a história do professor bilíngue, nas primeiras linhas do texto fica claro, como afirmou Marshall Sahlins, que "As antigas vítimas do colonialismo e do imperialismo descobriram sua cultura" (1997a, p. 129). Afinal, quem seria mais verdadeiramente autor de um projeto chamado História e Cultura Kaingang, se não os Kaingang?

Ainda na esteira do que observou Marshall Sahlins (1997b), reconhecer cientificamente que os grupos indígenas do mundo são sujeitos ativos e que não se sentem vítimas, mas protagonistas nos processos históricos, não significa ignorar uma série de violações que os setores hegemônicos das sociedades praticam ou ignoram que são praticadas contra estas pessoas, mas atentar para outra dimensão deste fenômeno:

[...] Aqueles povos que sobreviveram fisicamente ao assédio colonialista não estão fugindo à responsabilidade de elaborar culturalmente tudo o que lhes foi infligido. Eles vêm tentando 
incorporar o sistema mundial a uma ordem ainda mais abrangente: seu próprio sistema de mundo (SAHLINS, 1997b, p. 52).

Evidencia-se, por fim, que optando por viver em um pequeno espaço de mata em meio à área urbana de Lajeado, os Kaingang da Foxá vêm elaborando ações que visam melhorar suas vidas. Ao fazê-lo, não abandonam seus valores, língua, festas, artes, pelo contrário. Parecem estar cada vez mais fazendo emergir "cultura" a partir da sua cultura, em alusão à metáfora cunhada por Carneiro da Cunha (2009). Retomando Sahlins (1997b), o convite para que os fóg (brancos) participassem do Kikikoi parece mais um dos exemplos de “indianização da modernidade" que vêm sendo observados pelo mundo.

\section{Referências Bibliográficas:}

AQUINO, Alexandre Magno de. Ën Ga Vyg Ën Tóg (“Nós conquistamos nossa terra"): os Kaingang no litoral do Rio Grande do Sul. 214 f. Dissertação (Mestrado em Antropologia Social). PPGAS, UNB, Brasília, DF, 2008.

Movimentos kaingang na paisagem: transformações e alteridades nas configurações históricas do território e territorialidade no sul do Brasil. 345f. Tese (Doutorado), Porto Alegre, Universidade Federal do Rio Grande do Sul (UFRGS), Programa de Pós-Graduação em Antropologia Social (PPGAS), Rio Grande do Sul, Porto Alegre, 2018.

CUNHA, Manuela Carneiro da. Cultura com Aspas. Rio de Janeiro: Cosac e Naify, 2009.

BRINGHENTI, Clóvis Antônio. Movimento Indígena no Brasil. In: WITTMANN, Luisa Tombini (Org.). Ensino d(e) História Indígena. Belo Horizonte: Autêntica Editora, 2015, p. 143-176.

BUSOLLI, Jonathan. A Terra Indígena Pó Mág, Tabaí/RS no contexto da reterritorialidade Kaingang em áreas da Bacia Hidrográfica Taquari-Antas. 2015. 121 f. Graduação (Monografia). Curso de História, Centro Universitário UNIVATES, Lajeado, 2015.

CRÉPEAU, Robert R. "Os Kamé vão sempre primeiro": dualismo social e reciprocidade entre os Kaingang. Tempo Brasileiro. Anuário Antropológico. Rio de Janeiro, 2006, p. 9-33.

; ROSA, Rogério G. R. Actualité et transformations de la Fête des morts chez les Kaingang du Brésil meridional. Érudit. v. 19, n.2, 2018, p. 1-29.

DIÁRIO DE CAMPO de 11/12/2017. Pesquisa de Campo na Terra Indígena Foxá. Projeto de Extensão História e Cultura Kaingang. Lajeado: Univates, 11 jan. 2017, 5p. 
De 05/04/2019. Pesquisa de Campo na Terra Indígena Foxá. Projeto de Extensão História e Cultura Kaingang. Lajeado: Univates, 05 abr. 2019, 5p.

CUNHA, Manuela Carneiro da. História dos índios no Brasil. 2 ed. São Paulo: Editora Companhia das Letras, 1992.

FRANCISCO, Aline R. Kaingáng: Uma história das interações entre nativos e ocidentais durante a conquista e a colonização no sul do Brasil Meridional. 2013. 358 f. Tese (Doutorado) - Programa de Pós-Graduação em História (PPGH), Universidade Católica do Rio Grande do Sul, PUC-RS, Porto Alegre, 2013.

FREITAS, Ana Elisa de Castro. Mrũr Jykre - a cultura do cipó: territorialidades Kaingang na margem leste do Lago Guaíba, Porto Alegre, Rio Grande do Sul. 2005. 464 f. Tese (Doutorado em Antropologia Social) - PPGAS, UFRGS, Porto Alegre, RS, 2005.

FUNARI, Pedro Paulo; PIÑÓN, Ana. A Temática Indígena na Escola. São Paulo: Contexto, 2011.

GONÇALVES, Lylian Mares Cândido. Crianças indígenas Kaingang em escola não indígena: um estudo de caso envolvendo a Escola Estadual de Ensino Fundamental Manuel Bandeira, em Lajeado/RS. 2011. 74 f. Monografia (PósGraduação) - Especialização em Supervisão e Gestão Educacional, Centro Universitário Univates, Lajeado, 2011.

HISTÓRIA E CULTURA KAINGANG. Projeto de Extensão. Universidade do Vale do Taquari - Univates. 2016-2019, p. 1-15.

Acervo. Universidade do Vale do Taquari - Univates, 2009-2019.

LAPPE, Emelí. Natureza e Territorialidade: um estudo sobre os Kaingang das Terras Indígenas Linha Glória/Estrela, Por Fi Gâ/ São Leopoldo e Foxá/Lajeado. 2012. 133f. Monografia (Graduação) - Curso de História, Centro Universitário UNIVATES, Lajeado, 2012.

Espacialidades sociais e territoriais Kaingang: Terras Indígenas Foxá e Por Fi Gâ em contextos urbanos dos rios Taquari-Antas e Sinos. 207f. Dissertação (Mestrado), Programa de Pós-Graduação em Ambiente e Desenvolvimento (PPGAD). Centro Universitário Univates. Lajeado, 2015.

; LAROQUE, Luís. F. da S. Terra indígena Foxá "aqui no cedro": passado e presente Kaingang na sociedade do Vale do Taquari-RS-BR. Geousp - Espaço e Tempo (Online), v. 22, n. 1, p. 025-042, mês. 2018.

LAROQUE, Luís Fernando da Silva. Lideranças Kaingang no Brasil Meridional (1808-1889). Pesquisas. Antropologia no 56. São Leopoldo: Instituto Anchietano de Pesquisas/Unisinos, 2000.

MEINERZ, Carla B; PINHEIRO, Helen E. dos S. Educação das Relações ÉtnicoRaciais e Ensino de História: relações possíveis entre comunidades escolares e comunidades tradicionais. MÉTIS: história \& cultura. v. 17, n. 33, 2018, p. 151169.

MIGNOLO, Walter. Desafios descoloniais hoje. EPISTEMOLOGIAS DO SUL,v.1, n.1, 2017, p. 12-32. 
NICOLINI, Cristiano. A construção da identidade territorial a partir das manifestações culturais no Vale do Taquari: etnografia dos grupos de danças folclóricas alemãs de Estrela e do $47^{\circ}$ Festival do Chucrute. Santa Cruz do Sul, Dissertação (Mestrado), Universidade de Santa Cruz do Sul, 2013.

NOELLI, Francisco Silva; SOUZA, Jonas Gregorio de. Novas perspectivas para a cartografia arqueológica Jê no Brasil meridional. Boletim do Museu Paraense Emílio Goeldi. Ciências Humanas, v. 12, n. 1, p. 57-84, jan.-abr. 2017.

NOTZÖLD, Ana L. V; BRINGMANN, Sandor F. O Serviço de Proteção aos Índios e os projetos de desenvolvimento dos Postos Indígenas: o Programa Pecuário e a Campanha do Trigo entre os Kaingang da IR7. Revista Brasileira de História \& Ciências Sociais Vol. 5 № 10, Dezembro de 2013, p. 147-166.

OLIVEIRA, Marilda Dolores. Essa Terra já era Nossa: Um estudo histórico sobre o Grupo Kaingang na cidade de Lajeado. 2010. 89 f. Monografia (Graduação) - Curso de História, Centro Universitário Univates, Lajeado, 2010. OLIVEIRA, Luiz F de; CANDAU, Vera M. F. Pedagogia decolonial e educação antirracista e intercultural no Brasil. Educação em Revista, Belo Horizonte, v.26, n.01, 2010, p.15-40.

OSÓRIO, Helen. Apropriação da terra no Rio Grande de São Pedro e a formação do espaço platino. 1990. 248 f. Dissertação (Mestrado) - Programa de Pós-Graduação em História (UFRGS), Porto Alegre, 1990.

PAULA, João A. de. A extensão universitária: história, conceitos e proposta. Interfaces - Revista de Extensão, v. 1, n. 1, p. 05-23, jul./nov. 2013.

POLLAK, Michael. Memória e identidade social. In: Estudos Históricos, Rio de Janeiro, vol. 5, n.10, 1992, p. 200-212.

PRESTES, Fabiane da S. O bem viver Kaingang: as conexões entre os princípios da teoria do buen vivir e os saberes tradicionais que orientam o seu modo de ser. 279f. Tese 69 (Doutorado) - Programa de Pós-Graduação em Ambiente e Desenvolvimento, Universidade do Vale do Taquari - UNIVATES, Lajeado, 2018.

PROJETO de Extensão História e Cultura Kaingang. Lajeado: Universidade do Vale do Taquari - Univates, 2016 a 2019.

RODRIGUES, Cíntia R. As populações nativas sob a luz da modernidade: a proteção fraterna no Rio Grande do Sul (1908-1928). 226f. Tese (Doutorado) Programa de Pós-Graduação em História (PPGH), Universidade do Vale dos Sinos (UNISINOS), São Leopoldo, 2007.

SILVA, Juciane Beatriz Sehn da. Territorialidade Kaingang: um estudo da aldeia Kaingang Linha Glória, Estrela -RS. 2011, 125 f, Monografia (Graduação) - Curso de Licenciatura em História, Centro Universitário Univates, Lajeado, jul. 2011. 
SILVA, Edson. Ensino e sociodiversidades indígenas: possibilidades, desafios e impasses a partir da Lei 11.645/2008. Mneme - revista de humanidades. V. 15, n. 35, 2014, p. 21-37.

SAHLINS, Marshall. "O pessimismo sentimental" e a experiência etnográfica: Por que a cultura não é um "objeto" em via de extinção (Parte I). Revista Mana, v. 3, n. 1, p. 41-73, abr. $1997 b$.

"O pessimismo sentimental" e a experiência etnográfica: Por que a cultura não é um "objeto" em via de extinção (Parte II). Revista Mana, v. 3, n. 2, p. 103-150, out. 1997a.

SIMONIAN. Ligia T. Lopes. Política anti-indígena de Leonel de Moura Brizola. In: TAU Golin, Nelson (orgs). Povos indígenas - Volume 5. Passo Fundo-RS: Méritos Editora, 2009. p.469-496. (Coleção: História Geral do Rio Grande do Sul).

VEIGA, Juracilda. Organização Social e Cosmovisão Kaingang: uma introdução ao parentesco, casamento e nominação em uma sociedade Jê Meridional. 1994. 282f. Dissertação (Mestrado) - Programa de Pós-Graduação em Antropologia Social (PPGAS), Universidade de São Paulo (USP).

TOMMASINO, Kimiye. A história dos Kaingáng da bacia do Tibagi: uma Sociedade Jê Meridional em movimento. 1995. 348f. Tese (Doutoramento em Antropologia) - FFLCH, USP, São Paulo, SP, 1995. 